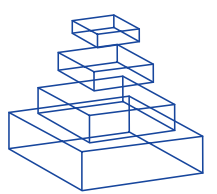

\title{
Growth factors and feeder cells promote differentiation of human embryonic stem cells into dopaminergic neurons: a novel role for fibroblast growth factor-20
}

\author{
Ana Sofia Correia ${ }^{*}$, , Sergey V. Anisimov ${ }^{*}$, , Jia-Yi Li ${ }^{*}$ and Patrik Brundin ${ }^{*}$, \\ * Neuronal Survival Unit, Department of Experimental Medical Science, Lund University, Wallenberg \\ Neuroscience Center, Lund, Sweden. \\ ₹ Present Address: S.V.A., Almazov Federal Center for Heart, Blood and Endocrinology Centre, \\ Saint-Petersburg, Russia; Cureline, Inc., Burlingame, USA
}

Edited by:

Javier DeFelipe, Cajal

Institute (CSIC), Spain

Reviewed by:

Jun Takahashi, Kyoto

University, Japan

Brigitte Onteniente, Institut

National de la Santé et de

la Recherche Médicale, France

†Correspondence:

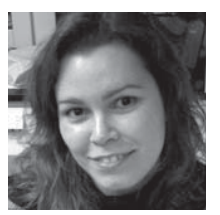

Ana-Sofia Correia obtained her degree in 2002 in Biological Engineering at Instituto Superior Técnico, Universidade Técnica de Lisboa, Lisbon, Portugal. Between 2003 and 2008, she was a PhD student in the research group of Dr. Patrik Brundin at the Wallenberg Neuroscience Center, Lund University, Sweden. Her PhD project focused on human embryonic stem cells with the goal to develop a cell-based therapy for Parkinson disease. She currently is a post-doc in the laboratory of Vivianne Tabar at the Sloan Kettering Cancer Research Institute in New York, NY, USA.

Sofia.Correia@med.lu.se

Human embryonic stem cells (hESCs) are a potential source of dopaminergic neurons for treatment of patients with Parkinson's disease (PD). Dopaminergic neurons can be derived from hESCs and display a characteristic midbrain phenotype. Once transplanted, they can induce partial behavioral recovery in animal models of PD. However, the potential research field faces several challenges that need to be overcome before clinical application of hESCs in a transplantation therapy in PD can be considered. These include low survival of the hESC-derived, grafted dopaminergic neurons after transplantation; unclear functional integration of the grafted neurons in the host brain; and, the risk of teratoma/tumor formation from the transplanted cells. This review is focused on our recent efforts to improve the survival of hESC-dervied dopaminergic neurons. In a recent study, we examined the effect of fibroblast growth factor (FGF)-20 in the differentiation of hESCs into dopaminergic neurons. We supplemented cultures of hESCs with FGF-20 during differentiation on PA6 mouse stromal cells for 3 weeks. When we added FGF-20 the yield of neurons expressing tyrosine hydroxylase increased. We demonstrated that at least part of the effect is contributed by enhanced cell differentiation towards the dopaminergic phenotype as well as reduced cell death. We compare our results with those obtained in other published protocols using different sets of growth factors. Taken together, our data indicate that FGF-20 has potent effects to generate large number of dopaminergic neurons derived from hESCs, which may be useful for hESC-based therapy in PD.

Keywords: human embryonic stem cells, fibroblast growth factor-20, dopaminergic neurons, differentiation, Parkinson's disease, stem cell therapy, apoptosis, caspase-3

\section{INTRODUCTION}

The motor symptoms in Parkinson's disease (PD) are primarily due to the loss of a single cell type, i.e. the dopaminergic neurons located in the substantia nigra pars compacta that project to the putamen and caudate nucleus. Due to the relatively restricted neuropathology, $\mathrm{PD}$ is considered a suitable disease for cell replacement-based therapy. Transplantation of mesencephalic tissue from human embryos, obtained from therapeutic abortions has provided proof-of-concept that PD can be treated with cell therapy (for review see Morizane et al., 2008). However, not all patients have improved after transplanted with embryonic mesencephalic tissue and subsets of patients have developed troubling dyskinesias (Freed et al., 2001; Hagell and Cenci, 2005; Hagell et al., 2002; Levivier et al., 1997; Olanow et al., 2003). Furthermore, this source of dopaminergic 


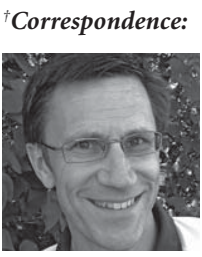

Patrik Brundin is a renowned researcher in the area of neurodegenerative diseases. In 1988 he obtained his $\mathrm{PhD}$ at Lund University, Sweden, on intracerebral transplantation in Parkinson disease. He was part of the team that conducted the first successful cell transplantation trials in Parkinson disease in 1989. In 2000 he was appointed professor of neuroscience at Lund University. He presently heads the Neuronal Survival Unit. It is devoted to understanding disease mechanisms in neurodegenerative disorders and developing restorative therapies in Parkinson and Huntington diseases. Patrik.Brundin@med.lu.se neurons is not readily obtainable, it is heterogeneous in cell composition and its application is inherently connected to ethical issues related to the abortion. An ideal source of cell material should be available in large quantities in a predictable manner, it should be highly enriched in midbrain dopaminergic neurons, and safe to transplant with no risks of infection or tumor growth.

Human embryonic stem cells (hESCs) derived from the inner cell mass of human blastocysts are such a potential source of cells. These cells are pluripotent and can self-renew (allowing massive expansion). It has already been demonstrated that they can generate dopaminergic neurons in culture (Ben-Hur et al., 2004; Brederlau et al., 2006; Cho et al., 2008; Iacovitti et al., 2007; Ko et al., 2007; Park et al., 2004, 2005; Perrier et al., 2004; Roy et al., 2006; Schulz et al., 2004; Sonntag et al., 2007; Ueno et al., 2006; Yan et al., 2005; Yang et al., 2007; Zeng et al., 2004) (Table 1). Improving the survival and functional integration of hESC-derived dopaminergic neurons after transplantation is a major challenge that has to be overcome before clinical application of hESCs is even to be considered in PD (Björklund et al., 2008; Correia et al., 2005; Deierborg et al., 2008; Hall et al., 2007; Morizane et al., 2008). Dopaminergic neurons derived from hESCs are functional in vitro, as shown by their ability to generate action potentials and release dopamine (Brederlau et al., 2006; Hong et al., 2008; Ko et al., 2007; Park et al., 2005; Perrier et al., 2004; Roy et al., 2006; Yan et al., 2005; Zeng et al., 2004). However, only a few studies have demonstrated that hESC-derived grafts can contain considerable numbers of tyrosine hydroxylase (TH)-expressing neurons and have claimed that they consistently induce behavioral improvement in the unilateral 6-hydroxydopamine (6-OHDA)-lesion rat model of PD (Cho et al., 2008; Ko et al., 2007; Roy et al., 2006; Yang et al., 2007).

Previous studies suggest that approximately 100,000 surviving dopaminergic neurons are needed in the grafts on each side of the brain in a PD patient in order to obtain any clinical benefits after transplantation (Hagell and Brundin, 2001). For rats with unilateral 6-OHDA lesions of the nigrostriatal pathway, only 1000 dopaminergic neurons must survive for the transplants to exert a significant effect on amphetamine-induced rotation around 6 weeks after surgery (Nakao et al., 1994). Therefore, obtaining a large fraction of hESCs that differentiate into dopaminergic neurons in vitro would be an important step towards success of a cell-based therapy for PD. For this reason, we recently studied the effect of a known midbrain dopaminergic trophic factor, fibroblast growth factor (FGF)-20 (Ohmachi et al., 2000, 2003), on the differentiation of hESCs into dopaminergic neurons and their subsequent survival in vitro. Earlier work has shown that FGF-20 increases the number of TH-expressing neurons derived from neural stem cells in vitro (Grothe et al., 2004; Takagi et al., 2005). Expression of this growth factor is specific to the substantia nigra in the rat brain (Ohmachi et al., 2000). In addition, the FGF-20 receptor, FGFR1c, is highly expressed by TH-positive neurons in the substantia nigra and is present at lower levels in other brain regions (Ohmachi et al., 2003). In serum-free cultures of primary rat mesencephalic tissue, FGF-20 only prevents the death of the TH-expressing cells and does not affect the total number of neurons yielded (Ohmachi et al., 2000, 2003). Moreover, certain Fgf20 gene haplotypes are associated with the increased risk of PD (van der Walt et al., 2004). In our recently published study we found that addition of FGF-20 during differentiation of hESCs also increases the yield of dopaminergic neurons, probably both by promoting differentiation of the stem cells and by decreasing apoptosis among the differentiated neurons (Correia et al., 2007).

\section{FACTORS THAT INCREASE THE EFFICIENCY IN THE DIFFERENTIATION OF hESCS INTO DOPAMINERGIC NEURONS IN VITRO}

Recent years have seen a dramatic number of studies describing the effects of a plethora of growth factors and feeder cells on the development of neural cells from ESCs. It is believed that ESCs differentiate into neuronal cells "by default", if not presented with stimuli that drive towards an alternative fate. These stimuli may be either soluble growth factors, or signaling elicited by cell-tocell contact. Bone morphogenic proteins (BMPs) suppress neuronal differentiation. For this reason, addition of Noggin, a BMP antagonist, increases the commitment of hESCs to a neuronal fate during differentiation (Ben-Hur et al., 2004; Iacovitti et al., 2007; Pera et al., 2004; Sonntag et al., 2007). Two major in vitro systems that induce neuronal differentiation of ESCs are the formation of embryoid bodies (Carpenter et al., 2001; Park et al., 2004; Schulz et al., 2003; Zhang et al., 2001) and the co-culturing with a layer of specific feeder cells (Perrier et al., 2004; Roy et al., 2006; Zeng et al., 2004). In suspension cultures, ESCs spontaneously aggregate, differentiate and form spherical embryoid bodies containing precursor cells of all three germ layers (mesoderm, endoderm and neuroectoderm). By supplementing the culture medium with certain mitogenic factors, such as epidermal growth factor (EGF) and basic fibroblast growth factor (bFGF), neural precursor cells can be expanded further. Alternatively, co-culturing 


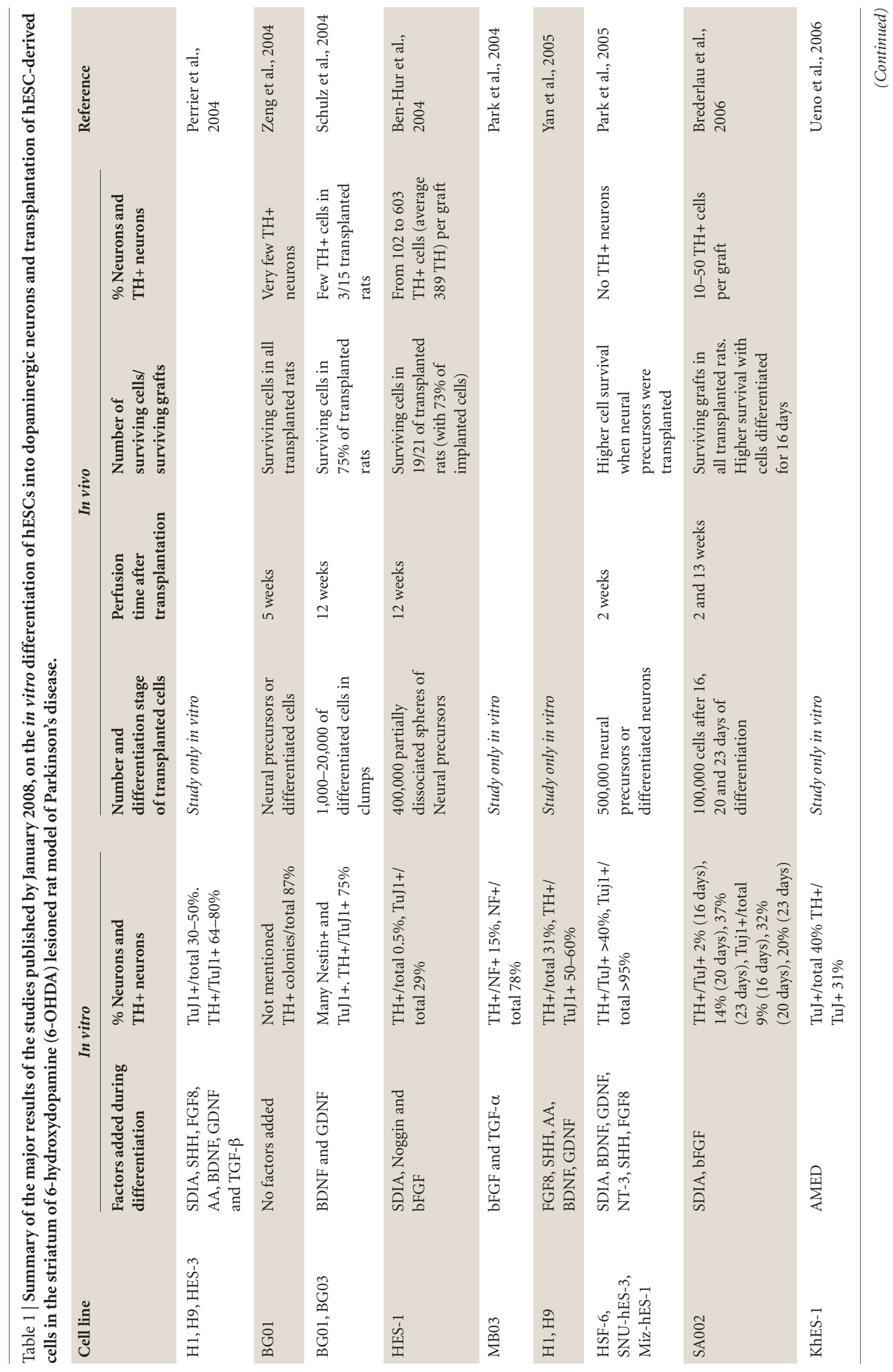




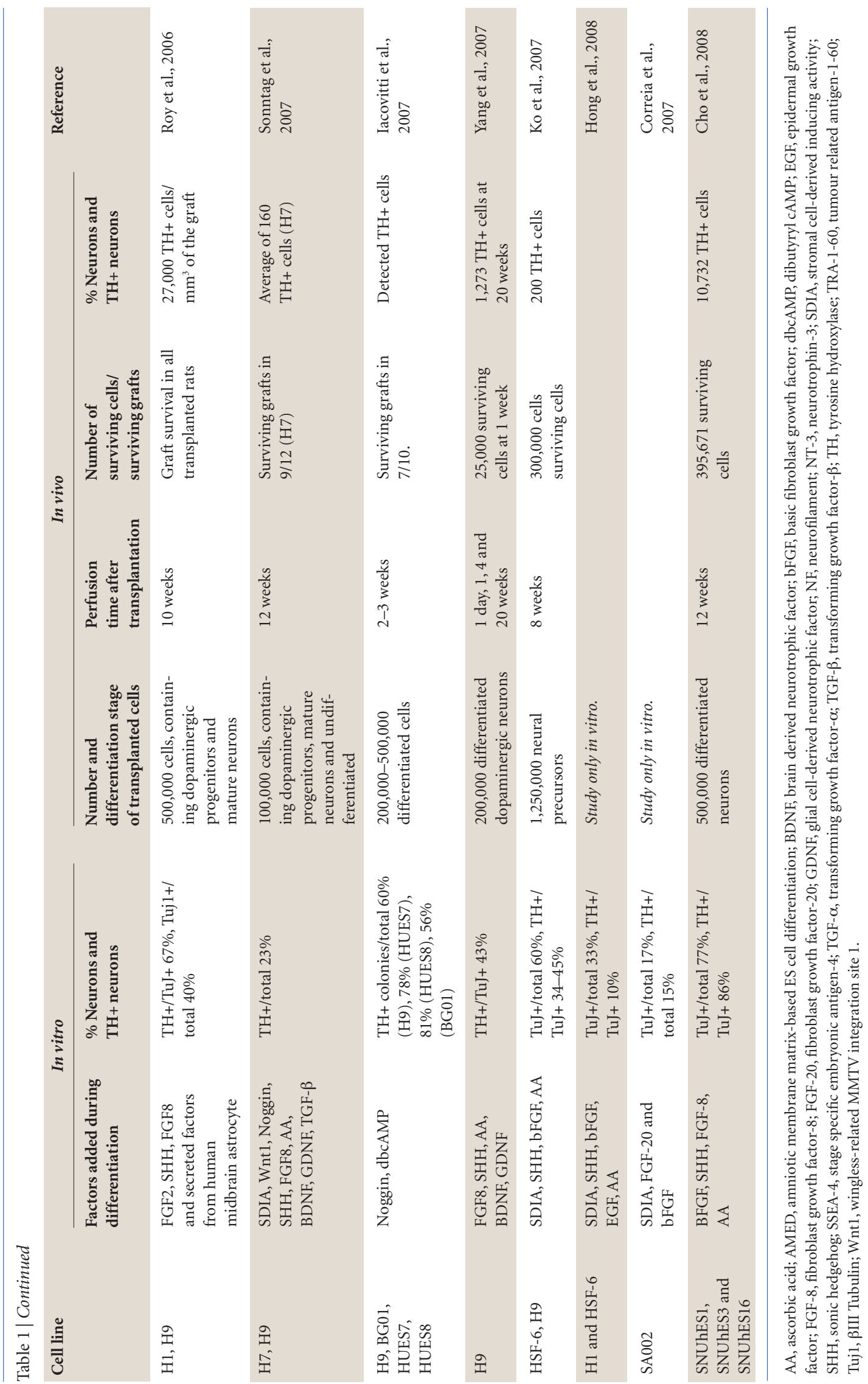


of ESCs with specific feeder cells induces their differentiation into neurons. Feeder cells with such properties include: (1) mouse stromal cell line PA6, isolated from mouse skull bone (also known as MC3T3-G2) (Park et al., 2005; Zeng et al., 2004); (2) mouse stromal cell line MS5, derived from the aorta-gonad-mesonephron (Hong et al., 2008; Ko et al., 2007; Perrier et al., 2004; Sonntag et al., 2007); (3) amniotic membrane matrix (Ueno et al., 2006) and (4) human midbrain astrocytes (Roy et al., 2006). Stromal cell-derived inducing activity (SDIA) is the name given to the activity of factors produced by the stromal cells that promote neuronal differentiation of ESCs (Kawasaki et al., 2000), which have still not been fully identified (Hayashi et al., 2008; Kawasaki et al., 2000; Yamazoe et al., 2005; Zeng et al., 2004). In the same way, the differentiation factors produced by the amniotic membrane matrix and human midbrain astrocytes are also still not completely defined (Roy et al., 2006; Ueno et al., 2006).

Different soluble factors, which are known to be involved in the development and maintenance of the midbrain dopaminergic system in vivo, have been used to induce the dopaminergic differentiation of hESCs in vitro (see Table 1). Sonic hedgehog $(\mathrm{SHH})$ and FGF-8 are involved in the patterning of mesencephalic dopaminergic neurons (Ye et al., 1998). Addition of FGF-8 into a co-culture system with PA6 feeder cells genetically modified to overexpress $\mathrm{SHH}$ leads to a substantial increase in the number of neurons expressing TH (Park et al., 2005). Transforming growth factor (TGF)- $\alpha$ is present in early embryonic structures where midbrain dopaminergic neurons develop. This factor is believed to be essential for both induction and survival of dopaminergic neurons in vitro and in vivo (Farkas et al., 2003). After culturing in the presence of TGF- $\alpha$ for 21 days, about $15 \%$ of the hESC-derived cells become TH-positive and release dopamine (Park et al., 2004). Perrier and co-workers combined co-culture with addition of different soluble factors in their differentiation protocol. They co-cultured hESCs with MS5 cells overexpressing wingless-related MMTV integration site 1 (Wnt1), and the culturing medium was sequentially supplemented by combinations of the following factors $\mathrm{SHH}, \mathrm{FGF}-8$, brain-derived neurotrophic factor (BDNF), GDNF, TGF- $\beta 3$, dibutyryl cAMP (dbcAMP) and ascorbic acid (AA). The sequential addition of a combination of these factors presumably imitates the development of the midbrain in vivo. Thereby it leads to the expression of transcription factors typical for midbrain neurons in a sequence similar to that observed during normal development. After 50 days exposure to those growth factors, over $100 \mathrm{TH}$-positive neurons could be generated from each undifferentiated hESC initially plated, which is the highest yield reported to date (Perrier et al., 2004).

In our own experiments, when we co-cultured hESCs with PA6 feeders in presence of $1 \mathrm{ng} / \mathrm{ml}$ FGF-20, we observed a 5-fold increase in the yield of hESC-derived TH-positive neurons (Figures 1 and 2). The percentage of $\mathrm{TH}$-expressing neurons among the total hESC-derived cells increased from $3 \%$ in the absence of FGF-20 to $15 \%$ in its presence (Correia et al., 2007). In concordance with our results, FGF-20 treatment of monkey ESCs during differentiation also resulted in a 5-fold increase (from $5 \%$ to $24 \%$ ) in the percentage of $\mathrm{TH}$-positive neurons within the total number of neurons (Takagi et al., 2005).

\section{HOW DOES FGF-20 PROMOTE THE INCREASE IN THE YIELD OF DOPAMINERGIC NEURONS FROM hESCs?}

The underlying mechanism by which FGF-20 enhances the yield of stem cell-derived dopaminergic neurons still remains unclear (Takagi et al., 2005). In our study, supplementation of culture media with FGF-20 did not increase cell proliferation. However, it decreased the fraction of apoptotic cells, as detected by the presence of cleaved caspase- 3 (from $2.5 \%$ without FGF -20 to $1.2 \%$ with FGF-20, out of the total hESC-derived cells, Figures 1 and 2) (Correia et al., 2007). Therefore, we conclude that FGF-20 increases the yield of TH-positive neurons via increased dopaminergic differentiation and reduced apoptotic cell death. Furthermore, we did not observe an effect of FGF-20 on the percentage of cells positive for $\beta$ IIITubulin (about 17\% out of the total hESC-derived cells in both conditions, Figure 1), indicating that it did not increase overall neuronal differentiation.

Using immunocytochemistry (Correia et al., 2007) and gene expression analysis (Anisimov et al., 2007), we detected the presence of FGFR-1 in undifferentiated hESCs, PA6 cells and hESC-derived TH-positive neurons. This suggests that FGF-20 could act (1) on the pluripotent hESCs, promoting their differentiation into dopaminergic neurons; and/or (2) directly on hESC-derived dopaminergic neurons to increase their survival; and/or (3) on the PA6 cells, inducing them to produce factors that promote differentiation and survival of dopaminergic neurons. It has been previously suggested that FGF-20, in a different cell culture paradigm, has an indirect mode of action on dopaminergic differentiation mediated by Schwann cells (Grothe et al., 2004).

FGF-20 has been suggested to activate antiapoptotic defenses in cultured rat mesencephalic dopaminergic neurons, particularly in calbindinnegative A9 dopaminergic neurons, i.e. those 


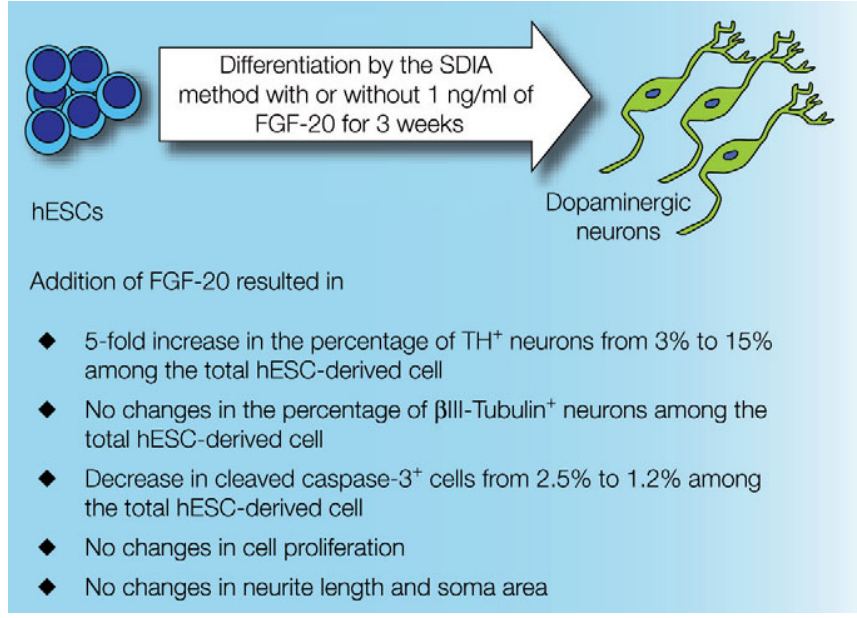

Figure 1 | Major findings of the treatment with FGF-20 of hESCs cultures during dopaminergic differentiation by co-culturing with PA6 cells.

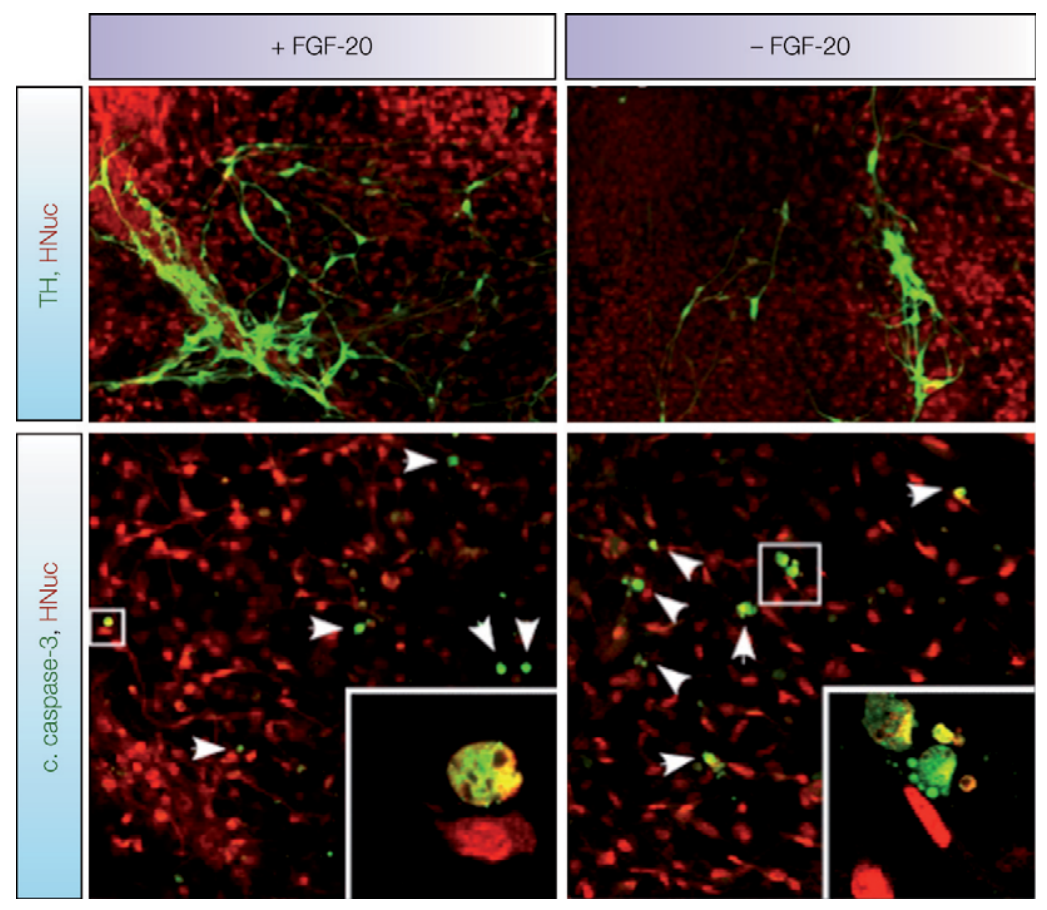

Figure 2 | Representative images of TH-, cleaved caspase-3- and HNuc-positive cells in 3 weeks differentiated hESCs/PA6 co-cultures untreated and treated with FGF-20 (-FGF-20 and +FGF-20, respectively, adapted from Correia et al., 2007).

located in the substantia nigra pars compacta (Murase and McKay, 2006; Ohmachi et al., 2000, 2003). We observed a significant difference in the number of cells positive for cleaved caspase- 3 in FGF-20-supplemented cultures (1.2\%), compared to untreated cultures $(2.5 \%)$. Furthermore, we also observed lower numbers of cells positive for the apoptotic markers cleaved caspase- 8 and $\mathrm{Bcl} 2$ associated X protein (BAX), when we added FGF-20 to the cultures. Cleaved caspase- 8 is involved in initiating the extrinsic cell death pathway, while BAX polymerization mediates mitochondrial cytochrome $\mathrm{C}$ release, which initiates the intrinsic pathway (Riedl and Shi, 2004). We therefore hypothesize that FGF-20 inhibits apoptosis of hESC-derived cells that is triggered through both the extrinsic and intrinsic pathways. The possible effect of FGF-20 in reducing cell death through apoptosis has been suggested by a previous study from Murase and McKay. In this study it was demonstrated FGF-20 promotes Bad phosphorylation, induced by PI3K activation, and Bax downregulation, due to p53 degradation (Murase and McKay, 2006). However, there is still no clear evidence of a direct relationship between FGF-20 and the apoptosis mechanisms. For this reason, the lower number of dying cells in the presence of FGF-20 might as well result from an improved cell survival through other pathways.

The percentages of cells exhibiting cleaved caspase- 3 at the time of fixation (21 days after starting the co-culture) were small. However, it has to be emphasized that detection of cleaved caspase- 3 is limited to a number of hours, until the cells eventually lyse and disappear from the culture (Correia et al., 2007). In essence we are only providing a "snapshot" of the cells that are dying at a particular time point in the culture procedure. Therefore, these values can be seen to underestimate the protective effect of FGF-20, and do not reflect the cells that had died throughout the whole culture experiment, which lasted for 21 days. If the rate of cell death is similar over the whole 21-day culture period and dying/dead cells remain positive for cleaved caspase 3 during approximately $12 \mathrm{~h}$, we can estimate a $52 \%$ reduction in cell death in the presence of FGF-20. The lower cell death in the FGF-20-treated cultures can result in a substantial increase in living $\mathrm{TH}$-positive neurons. Unfortunately, we were not able to definitively determine if the dying neurons were dopaminergic. The identification of dying dopaminergic neurons in culture is not easily achieved, because dying cells downregulate cytosolic proteins such as TH (Burke, 2004). As a result, the fact that we did not detect cells immunopositive for both $\mathrm{TH}$ and cleaved caspase-3, does not clarify the issue of whether the cells positive for cell death markers were dopaminergic or not. Using for example a reporter gene coupled to $\mathrm{TH}$ and live cell imaging would be one method to address this issue systematically.

\section{HOW COULD FGF-20 CONTRIBUTE TO THE DEVELOPMENT OF A CELL-BASED THERAPY FOR PARKINSON'S DISEASE?}

One of the major limitations in the development of a cell therapy for PD is that dopaminergic neurons 

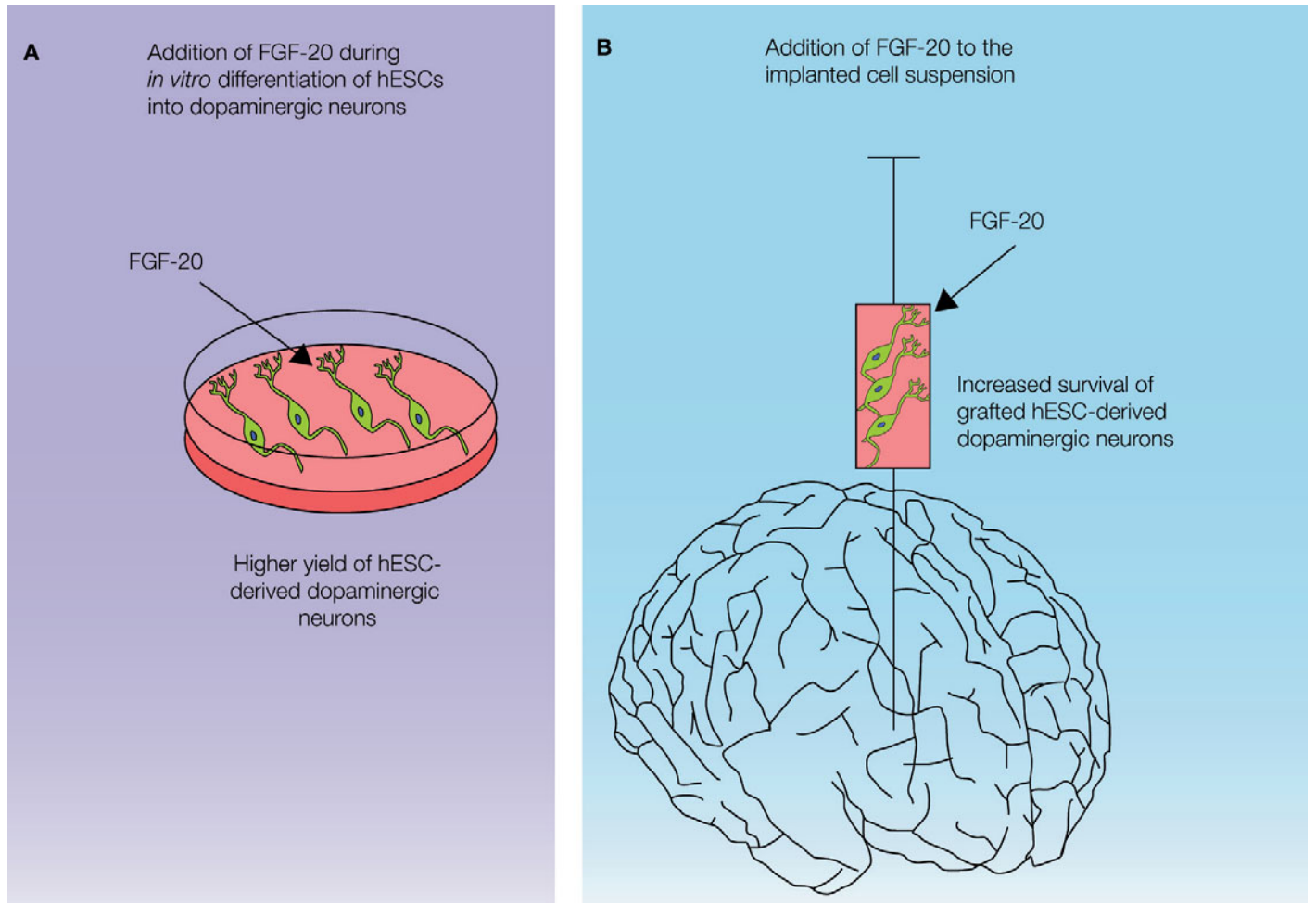

Figure 3 | Possible applications of FGF-20 in a cell-based therapy for Parkinson's disease.

survive poorly when transplanted (Ben-Hur et al., 2004; Brederlau et al., 2006; Park et al., 2005; Zeng et al., 2004). Therefore, the high yield of dopaminergic neurons obtained from hESCs in the presence of FGF-20 might provide a direct advantage for neural transplantation in PD. Previous studies showed that treatment of intrastriatal implants of embryonic mesencephalic tissue with neurotrophic factors, such as GDNF, BDNF, neurotrophin (NT)-4/5, NT-3, NTN, nerve growth factor (NGF), growth/differentiation factor (GDF)-5, insulin-like growth factor (IGF)-1, TGF- $\beta$, acidic FGF (aFGF) and basic FGF (bFGF), increases the survival rates of TH-positive neurons to approximately 30-35\% (Brundin et al., 2000; Sortwell, 2003). Additionally, it affects the functional capacity of grafted dopaminergic neurons (Brundin et al., 2000; Giacobini et al., 1993; Haque et al., 1996; Rosenblad et al., 1996, 1999; Sortwell, 2003; Sullivan et al., 1998; Yurek et al., 1996). In future studies we intend to investigate if FGF-20 can enhance neuronal survival of hESC-derived TH-positive neurons after grafting.

Numerous factors have been claimed to compromise the survival of mesencephalic dopaminergic neurons from human embryos during transplantation. Those factors include hypoxia, oxidative stress and trophic factor withdrawal. Similar factors are also likely to affect the survival of dopaminergic neurons derived from hESCs. Treatment with, e.g., antioxidants and trophic factors is beneficial to grafts of primary mesencephalic neurons (Brundin et al., 2000; Sortwell,2003).Similar treatments mayincrease the survival of grafted hESC-derived dopamine neurons. Based on the published reports and on our own data (Correia et al., 2007; Murase and McKay, 2006; Ohmachi et al., 2000, 2003), we hypothesize that FGF-20 could be used to improve graft survival by treating cells during/after implantation. In addition to the effects on hESC differentiation, it may also be added to the cell suspension during transplantation, improving the survival of the dopaminergic neuros in vivo (Figure 3). Another option would be to generate a viral vector expressing FGF-20 and co-injecting it with the transplant cells. It is also conceivable that a viral vector expressing FGF-20 could be tested in animal models of PD, with the ultimate aim of translating the technique to the clinic and reducing the progressive degeneration of dopamine neurons in PD. Obviously, safety aspects and potentially undesirable effects (e.g. inflammation, proliferation of mesenchymal cells etc) of long-term administration of FGF-20 to the brain must first be carefully explored.

\section{CONCLUSIONS}

We believe that in the future FGF-20 supplementation should be incorporated in the hESC-based in vitro differentiation protocols intent to derive the dopaminergic neurons. This adaptation will 
increase yield of large quantities of dopaminergic neurons with a classical substantia nigra phenotype from hESCs. In order to improve the survival of the hESC-derived dopaminergic neurons during transplantation, FGF-20 could also be added to the cell suspension during implantation. Further studies are needed to examine the survivability and functionality of the dopaminergic neurons derived from the hESCs in the presence of FGF-20, and also the trophic effect of FGF-20 in the implanted cells.

\section{CONFLICT OF INTEREST STATEMENT}

The authors declare that the research was conducted in the absence of any commercial or financial relationships that could be construed as a potential conflict of interest.

\section{ACKNOWLEDGMENTS}

The authors thank Ingrid Sandelin and Ingar Nilsson for their excellent technical support and Birgitta Larsson for her help in grant administration. We thank Laurent Roybon for helpful discussions. This study was supported by the following grants: NeuroFortis (IS, IN); Thorsten och Elsa Segerfalks Stiftelse (JYL); Grants from the Swedish Research Council (PB, JYL); Crafoordska Stiftelsen (JYL, SVA); Swedish Parkinson Foundation (JYL, SVA); Torsten och Ragnar Söderbergs stiftelser (PB); Stiftelsen Olle Engkvist Byggmästare (PB); Konung Gustaf V:s och Drottning Victorias Stiftelse (PB); Swedish Brain Foundation (PB) and Fundação para a Ciência e Tecnologia (ref SFRH/ $\mathrm{BD} / 11804 / 2003$ to ASC).

\section{REFERENCES}

Anisimov, S. V., Christophersen, N. S., Correia, A. S., Li, J. Y., and Brundin, P. (2007). "NeuroStem Chip": a novel highly specialized tool to study neural differentiation pathways in human stem cells. BMC Genomics 8, 46.

Ben-Hur, T., Idelson, M., Khaner, H., Pera, M., Reinhartz, E., Itzik, A., and Reubinoff, B. E. (2004). Transplantation of human embryonic stem cell-derived neural progenitors improves behavioral deficit in Parkinsonian rats. Stem Cells 22, 1246-1255.

Björklund, T., Morizane, A., Kirik, D., and Brundin, P. (2008). Future cell- and gene-based therapies for Parkinson's disease. In Therapeutics of Parkinson's Disease and Other Movement Disorders, M. Hallett and W. Poewe, eds (Wiley Publications, John Wiley \& Sons, Ltd). [Epub ahead of print].

Brederlau, A., Correia, A. S., Anisimov, S. V., Elmi, M., Paul, G., Roybon, L., Morizane, A., Bergquist, F., Riebe, I., Nannmark, U., Carta, M., Hanse, E., Takahashi, J., Sasai, Y., Funa, K., Brundin, P., Eriksson, P. S., and Li, J. Y. (2006). Transplantation of human embryonic stem cell-derived cells to a rat model of Parkinson's disease: effect of in vitro differentiation on graft survival and teratoma formation. Stem Cells 24, 1433-1440.

Brundin, P., Karlsson, J., Emgard, M., Schierle, G. S., Hansson, O., Petersen, A., and Castilho, R. F. (2000). Improving the survival of grafted dopaminergic neurons: a review over current approaches. Cell Transplant. 9, 179-195.

Burke, R. E. (2004). Ontogenic cell death in the nigrostriatal system. Cell Tissue Res. 318, 63-72.

Carpenter, M. K., Inokuma, M. S., Denham, J., Mujtaba, T., Chiu, C. P., and Rao, M. S. (2001). Enrichment of neurons and neural precursors from human embryonic stem cells. Exp. Neurol. 172, 383-397.

Cho, M. S., Lee, Y. E., Kim, J. Y., Chung, S., Cho, Y. H., Kim, D. S., Kang, S. M., Lee, H., Kim, M. H., Kim, J. H., Leem, J. W., Oh, S. K., Choi, Y. M., Hwang, D. Y., Chang, J. W., and Kim, D. W. (2008). Highly efficient and large-scale generation of functional dopamine neurons from human embryonic stem cells. Proc. Natl. Acad. Sci. USA 105, 3392-3397.
Correia, A. S., Anisimov, S. V., Li, J. Y., and Brundin, P. (2005). Stem cell-based therapy for Parkinson's disease. Ann. Med. 37, 487-498.

Correia, A. S., Anisimov, S. V., Roybon, L., Li, J.-Y., and Brundin, P. (2007). Fibroblast growth factor20 increases the yield of midbrain dopaminergic neurons from human embryonic stem cells. Front. Neuroanat. 1, 4. doi: 10.3389/neuro.05/004.2007.

Deierborg, T., Soulet, D., Roybon, L., Hall, V. J., and Brundin, P. (2008). Emerging restorative treatments for Parkinson's disease. Prog. Neurobiol. doi: 10.1016/j.pneurobio.2008.05.001

Farkas, L. M., Dunker, N., Roussa, E., Unsicker, K., and Krieglstein, K. (2003). Transforming growth factor-beta(s) are essential for the development of midbrain dopaminergic neurons in vitro and in vivo. J. Neurosci. 23, 5178-5186.

Freed, C. R., Greene, P. E., Breeze, R. E., Tsai, W. Y., DuMouchel, W., Kao, R., Dillon, S., Winfield, H., Culver, S., Trojanowski, J. Q., Eidelberg, D., and Fahn, S. (2001). Transplantation of embryonic dopamine neurons for severe Parkinson's disease. N. Engl. J. Med. 344, 710-719.

Giacobini, M. M., Stromberg, I., Almstrom, S., Cao, Y., and Olson, L. (1993). Fibroblast growth factors enhance dopamine fiber formation from nigral grafts. Brain Res. Dev. Brain Res. 75, 65-73.

Grothe, C., Timmer, M., Scholz, T., Winkler, C., Nikkhah, G., Claus, P., Itoh, N., and Arenas, E. (2004). Fibroblast growth factor-20 promotes the differentiation of Nurr1-overexpressing neural stem cells into tyrosine hydroxylase-positive neurons. Neurobiol. Dis. 17, 163-170.

Hagell, P., and Brundin, P. (2001). Cell survival and clinical outcome following intrastriatal transplantation in Parkinson disease. J. Neuropathol. Exp. Neurol. 60, 741-752.

Hagell, P., and Cenci, M. A. (2005). Dyskinesias and dopamine cell replacement in Parkinson's disease: a clinical perspective. Brain Res. Bull. 68, 4-15.

Hagell, P., Piccini, P., Bjorklund, A., Brundin, P., Rehncrona, S., Widner, H., Crabb, L., Pavese, N., Oertel, W. H., Quinn, N., Brooks, D. J., and Lindvall, O. (2002). Dyskinesias following neural transplantation in Parkinson's disease. Nat. Neurosci. 5, 627-628.
Hall, V. J., Li, J. Y., and Brundin, P. (2007). Restorative cell therapy for Parkinson's disease: a quest for the perfect cell. Semin. Cell Dev. Biol. 18, 859-869.

Haque, N. S., Hlavin, M. L., Fawcett, J. W., and Dunnett, S. B. (1996). The neurotrophin NT4/5, but not NT3, enhances the efficacy of nigral grafts in a rat model of Parkinson's disease. Brain Res. 712, 45-52.

Hayashi, H., Morizane, A., Koyanagi, M., Ono, Y., Sasai, Y., Hashimoto, N., and Takahashi, J. (2008). Meningeal cells induce dopaminergic neurons from embryonic stem cells. Eur. J. Neurosci. 27, 261-268.

Hong, S., Kang, U. J., Isacson, O., and Kim, K. S. (2008). Neural precursors derived from human embryonic stem cells maintain long-term proliferation without losing the potential to differentiate into all three neural lineages, including dopaminergic neurons. J. Neurochem. 104, 316-324.

Iacovitti, L., Donaldson, A. E., Marshall, C. E., Suon, S., and Yang, M. (2007). A protocol for the differentiation of human embryonic stem cells into dopaminergic neurons using only chemically defined human additives: Studies in vitro and in vivo. Brain Res. 1127, 19-25.

Kawasaki, H., Mizuseki, K., Nishikawa, S., Kaneko, S., Kuwana, Y., Nakanishi, S., Nishikawa, S. I., and Sasai, Y. (2000). Induction of midbrain dopaminergic neurons from ES cells by stromal cellderived inducing activity. Neuron 28, 31-40.

Ko, J. Y., Park, C. H., Koh, H. C., Cho, Y. H., Kyhm, J. H., Kim, Y. S., Lee, I., Lee, Y. S., and Lee, S. H. (2007). Human embryonic stem cellderived neural precursors as a continuous, stable, and on-demand source for human dopamine neurons. J. Neurochem. 103, 1417-1429.

Levivier, M., Dethy, S., Rodesch, F., Peschanski, M., Vandesteene, A., David, P., Wikler, D., Goldman, S., Claes, T., Biver, F., Liesnard, C., Goldman, M., Hildebrand, J., and Brotchi, J. (1997). Intracerebral transplantation of fetal ventral mesencephalon for patients with advanced Parkinson's disease. Methodology and 6-month to 1-year follow-up in 3 patients. Stereotact. Funct. Neurosurg. 69, 99-111.

Morizane, A., Li, J. Y., and Brundin, P. (2008). From bench to bed: the potential of stem cells for the 
treatment of Parkinson's disease. Cell Tissue Res. 331, 323-336.

Murase, S., and McKay, R. D. (2006). A specific survival response in dopamine neurons at most risk in Parkinson's disease. J. Neurosci. 26, 9750-9760.

Nakao, N., Frodl, E. M., Duan, W. M., Widner, H., and Brundin, P. (1994). Lazaroids improve the survival of grafted rat embryonic dopamine neurons. Proc. Natl. Acad. Sci. USA 91, 12408-12412.

Ohmachi, S., Mikami, T., Konishi, M., Miyake, A., and Itoh, N. (2003). Preferential neurotrophic activity of fibroblast growth factor-20 for dopaminergic neurons through fibroblast growth factor receptor-1c. J. Neurosci. Res. 72, 436-443.

Ohmachi, S., Watanabe, Y., Mikami, T., Kusu, N., Ibi, T., Akaike, A., and Itoh, N. (2000). FGF-20, a novel neurotrophic factor, preferentially expressed in the substantia nigra pars compacta of rat brain. Biochem. Biophys. Res. Commun. 277, 355-360.

Olanow, C. W., Goetz, C. G., Kordower, J. H., Stoessl, A. J., Sossi, V., Brin, M. F., Shannon, K. M., Nauert, G. M., Perl, D. P., Godbold, J., and Freeman, T. B. (2003). A double-blind controlled trial of bilateral fetal nigral transplantation in Parkinson's disease. Ann. Neurol. 54, 403-414.

Park, C. H., Minn, Y. K., Lee, J. Y., Choi, D. H., Chang, M. Y., Shim, J. W., Ko, J. Y., Koh, H. C., Kang, M. J., Kang, J. S., Rhie, D. J., Lee, Y. S., Son, H., Moon, S. Y., Kim, K. S., and Lee, S. H. (2005). In vitro and in vivo analyses of human embryonic stem cell-derived dopamine neurons. J. Neurochem. 92, 1265-1276.

Park, S., Lee, K. S., Lee, Y. J., Shin, H. A., Cho, H. Y., Wang, K. C., Kim, Y. S., Lee, H. T., Chung, K. S., Kim, E. Y., and Lim, J. (2004). Generation of dopaminergic neurons in vitro from human embryonic stem cells treated with neurotrophic factors. Neurosci. Lett. 359, 99-103.

Pera, M. F., Andrade, J., Houssami, S., Reubinoff, B., Trounson, A., Stanley, E. G., Ward-van Oostwaard, D., and Mummery, C. (2004). Regulation of human embryonic stem cell differentiation by BMP-2 and its antagonist noggin. J. Cell Sci. 117, 1269-1280.

Perrier, A. L., Tabar, V., Barberi, T., Rubio, M. E., Bruses, J., Topf, N., Harrison, N. L., and Studer, L. (2004). Derivation of midbrain dopamine neurons from human embryonic stem cells. Proc. Natl. Acad. Sci. USA 101, 12543-12548.

Riedl, S. J., and Shi, Y. (2004). Molecular mechanisms of caspase regulation during apoptosis. Nat. Rev. Mol. Cell Biol. 5, 897-907.

Rosenblad, C., Kirik, D., and Bjorklund, A. (1999). Neurturin enhances the survival of intrastriatal fetal dopaminergic transplants. Neuroreport 10, 1783-1787.

Rosenblad,C., Martinez-Serrano,A., and Bjorklund, A. (1996). Glial cell line-derived neurotrophic factor increases survival, growth and function of intrastriatal fetal nigral dopaminergic grafts. Neuroscience 75, 979-985.

Roy, N. S., Cleren, C., Singh, S. K., Yang, L., Beal, M. F., and Goldman, S. A. (2006). Functional engraftment of human ES cell-derived dopaminergic neurons enriched by coculture with telomeraseimmortalized midbrain astrocytes. Nat. Med. 12, 1259-1268

Schulz, T. C., Noggle, S. A., Palmarini, G. M., Weiler, D. A., Lyons, I. G., Pensa, K. A., Meedeniya, A. C., Davidson, B. P., Lambert, N. A., and Condie, B. G. (2004). Differentiation of human embryonic stem cells to dopaminergic neurons in serum-free suspension culture. Stem Cells 22, 1218-1238.

Schulz, T. C., Palmarini, G. M., Noggle, S. A., Weiler, D. A., Mitalipova, M. M., and Condie, B. G. (2003). Directed neuronal differentiation of human embryonic stem cells. BMC Neurosci. 4, 27.

Sonntag, K. C., Pruszak, J., Yoshizaki, T., van Arensbergen, J., Sanchez-Pernaute, R., and Isacson, O. (2007). Enhanced yield of neuroepithelial precursors and midbrain-like dopaminergic neurons from human embryonic stem cells using the bone morphogenic protein antagonist noggin. Stem Cells 25, 411-418.

Sortwell, C. E. (2003). Strategies for the augmentation of grafted dopamine neuron survival. Front. Biosci. 8, s522-s532.

Sullivan, A. M., Pohl, J., and Blunt, S. B. (1998). Growth/ differentiation factor 5 and glial cell line-derived neurotrophic factor enhance survival and function of dopaminergic grafts in a rat model of Parkinson's disease. Eur. J. Neurosci. 10, 3681-3688.

Takagi, Y., Takahashi, J., Saiki, H., Morizane, A., Hayashi, T., Kishi, Y., Fukuda, H., Okamoto, Y., Koyanagi, M., Ideguchi, M., Hayashi, H., Imazato, T.,Kawasaki,H.,Suemori,H.,Omachi, S., Iida, H., Itoh, N., Nakatsuji, N., Sasai, Y., and Hashimoto, N. (2005). Dopaminergic neurons generated from monkey embryonic stem cells function in a Parkinson primate model. J. Clin. Invest. 115, 102-109.

Ueno, M., Matsumura, M., Watanabe, K., Nakamura, T., Osakada, F., Takahashi, M., Kawasaki, H., Kinoshita, S., and Sasai, Y. (2006). Neural conversion of ES cells by an inductive activity on human amniotic membrane matrix. Proc. Natl. Acad. Sci. USA 103, 9554-9559.

van der Walt, J. M., Noureddine, M. A., Kittappa, R., Hauser, M. A., Scott, W. K., McKay, R., Zhang, F.,
Stajich, J. M., Fujiwara, K., Scott, B. L., PericakVance, M. A., Vance, J. M., and Martin, E. R. (2004). Fibroblast growth factor 20 polymorphisms and haplotypes strongly influence risk of Parkinson disease. Am. J. Hum. Genet. 74, 1121-1127.

Yamazoe, H., Murakami, Y., Mizuseki, K., Sasai, Y., and Iwata, H. (2005). Collection of neural inducing factors from PA6 cells using heparin solution and their immobilization on plastic culture dishes for the induction of neurons from embryonic stem cells. Biomaterials 26, 5746-5754.

Yan, Y., Yang, D., Zarnowska, E. D., Du, Z., Werbel, B., Valliere, C., Pearce, R. A., Thomson, J. A., and Zhang, S. C. (2005). Directed differentiation of dopaminergic neuronal subtypes from human embryonic stem cells. Stem Cells 23, 781-790.

Yang, D., Zhang, Z. J., Oldenburg, M., Ayala, M., and Zhang, S. C. (2007). Human embryonic stem cell-derived dopaminergic neurons reverse functional deficit in Parkinsonian rats. Stem Cells 26, 55-63.

Ye, W., Shimamura, K., Rubenstein, J. L., Hynes, M. A., and Rosenthal, A. (1998). FGF and Shh signals control dopaminergic and serotonergic cell fate in the anterior neural plate. Cell 93, 755-766.

Yurek, D. M., Lu, W., Hipkens, S., and Wiegand, S. J. (1996). BDNF enhances the functional reinnervation of the striatum by grafted fetal dopamine neurons. Exp. Neurol. 137, 105-118.

Zeng, X., Cai, J., Chen, J., Luo, Y., You, Z. B., Fotter, E., Wang, Y., Harvey, B., Miura, T., Backman, C., Chen, G. J., Rao, M. S., and Freed, W. J. (2004). Dopaminergic differentiation of human embryonic stem cells. Stem Cells 22, 925-940.

Zhang, S. C., Wernig, M., Duncan, I. D., Brustle, O., and Thomson, J. A. (2001). In vitro differentiation of transplantable neural precursors from human embryonic stem cells. Nat. Biotechnol. 19, 1129-1133.

Received: 31 March 2008; accepted: 21 May 2008.

Citation: Front. Neurosci. (2008) 2, 1: 26-34, doi: 10.3389/neuro.01.011.2008

Copyright (C) 2008 Correia, Anisimov, Li and Brundin. This is an open-access article subject to an exclusive license agreement between the authors and the Frontiers Research Foundation, which permits unrestricted use, distribution, and reproduction in any medium, provided the original authors and source are credited. 